\title{
RISCO E PROTEÇÃO PARA O ENGAJAMENTO DE ADOLESCENTES EM PRÁTICAS DE ATOS INFRACIONAIS
}

\author{
RISK AND PROTECTION FOR ADOLESCENTS ENGAGED IN \\ PRACTICES OF OFFENSIVE CONDUCT
}

\author{
Maria Angélica de Souza da Silveira ${ }^{1}$, Maria Cristina Maruschi ${ }^{2}$, Marina Rezende Bazon ${ }^{3}$
}

\section{RESUMO:}

A adolescência é uma fase crucial do desenvolvimento humano, mas também é vulnerável devido à exposição a fatores de risco associados ao desenvolvimento de problemas adaptativos. No presente estudo objetivou-se apreender e descrever a experiência de adolescentes quanto à exposição a fatores de risco e de proteção no tocante ao desenvolvimento de comportamentos de risco, especificamente à conduta infracional, considerando informações em domínios destacados na literatura: família, desenvolvimento psicológico/atitudes/comportamento social, escola, relação com pares/ amigos, lazer/uso de álcool/drogas. Vinte e quatro adolescentes do sexo masculino foram entrevistados, sendo 12 deles considerados com boa adaptação social (recrutados em escola pública) e 12 apresentando conduta delituosa (recrutados em audiência de apresentação à Promotoria Pública, devido ao indiciamento policial por autoria de ato infracional). Visou-se dar relevo às variáveis que parecem agir no sentido de fomentar respostas desadaptativas, atuando como fator de risco, ou no de garantir respostas adaptativas, atuando como fator de proteção frente às adversidades. Os dados coletados foram submetidos à Análise de Conteúdo. Os resultados indicaram que os adolescentes com boa adaptação social, embora submetidos a fatores de risco, principalmente no âmbito da família, seriam expostos a mais fatores de proteção que os adolescentes infratores, especialmente no contexto escolar. Este grupo pode ser considerado, portanto, especialmente vulnerável devido à ausência de fatores proteção. Esse aspecto deve ser considerado por programas de intervenção de prevenção na área.

Palavras-chave: adolescente; risco; proteção; desenvolvimento social.

\section{ABSTRACT:}

Adolescence is a crucial stage of human development, and adolescents are vulnerable to risk factors associated with adaptations at the developmental stages. The objective of this study was to describe the experience of adolescents exposed to risks and the protective factors that lead to the development of risky behaviors, specifically offensive conduct, considering aspects highlighted in the literature, such as family; psychological development; attitude; social behavior; schooling; relationships with peers; leisure activities and alcohol and drugs use. Twenty-four male teenagers were interviewed, 12 of them considered with good social adaptation (recruited from public schools) and 12 had a criminal conduct (recruited from hearings at the District Attorney office). The aim was to underscore variables that appear to promote maladaptive responses, acting as a risk factors, and to ensure adaptive responses as protective factors against adversities. The data collected were subjected to the content analysis. The results indicated that adolescents with good social adjustment, although subject to risk factors, especially within the family, are exposed to more protective factors that youth offenders, especially in the school environment. This group can be considered, therefore, vulnerable due to lack of protective factors. This aspect should be considered in preventive interventional programs in this area.

Key words: adolescent; risk; protection; social development.

1 Pedagoga - Mestranda do Programa de Pós-graduação em Psicologia da UFAM. Localizada nos altos do Bloco Rio Uatumã, Campus Universitário, Setor Norte, Av. Rodrigo Otávio Jordão Ramos 3000, Manaus, Amazonas, CEP 69077-000.

2 Psicóloga - Tribunal de Justiça do Estado de São Paulo, Mestre em Ciências: Psicologia, Departamento de Psicologia e Educação Faculdade de Filosofia, Ciências e Letras de Ribeirão Preto, Universidade de São Paulo.

3 Professora Doutora - Depto. de Psicologia da Faculdade de Filosofia, Ciências e Letras de Ribeirão Preto/USP. Av. Bandeirantes, 3900 / Monte Alegre14040-901 - Ribeirão Preto - SP; Tel. 16-3602-3830, Fax. 16-3602-4835.

Instituição no qual o trabalho foi realizado: Faculdade de Filosofia, Ciências e Letras de Ribeirão Preto, Departamento de Psicologia e Educação - USP. O Trabalho foi subvencionado, por meio de concessão de bolsa Ensinar com Pesquisa à primeira autora, pela PróReitoria de Graduação da Universidade de São Paulo.

Correspondência para: mbazon@ffclrp.usp.br

Suggested citation: Da Silveira MAS, Maruschi MC, Bazon MR. Risk and protection for adolescents engaged in practices of illegal actions. J. Hum. Growth Dev. 2012; 22(3): 348-357

Manuscript submitted Mar 22 2012, accepted for publication Sep 162012 


\section{INTRODUÇÃO}

A adolescência é uma fase crucial para o desenvolvimento humano por que nela ocorrem processos relacionados a importantes aquisições cognitivas, emocionais e sociais, sendo um período propício para a formação de hábitos e padrões de comportamento ${ }^{1}$. Todavia é preciso considerar que os adolescentes constituem um dos grupos mais vulneráveis aos problemas que decorrem da estrutura e do funcionamento da sociedade ${ }^{2}$. Nesse sentido, a exposição dos jovens à violência se destaca, envolvendo o segmento como vítima e/ou como agressor. Nessa fase, além das intensas transformações físicas e psicológicas, existe maior permeabilidade às influências do meio; é quando o indivíduo começa a tornar-se independente dos pais, a dar mais valor aos pares e a explorar situações variadas com as quais pode ainda não saber lidar muito bem.

Há evidências de que nas últimas décadas, no Brasil, o fenômeno da violência envolvendo adolescentes como autores vem aumentando ${ }^{3,4}$. Notase, também, a diminuição cada vez mais acentuada da faixa etária dos jovens que praticam atos infracionais ${ }^{5,6}$. Esse tema tem sido bastante explorado, no Brasil, por todos os tipos de mídia, embora as investigações de natureza científica, buscando melhor entender o fenômeno, ainda sejam pouco numerosas. Tal panorama impõe a necessidade de conhecer as variáveis que, no contexto sócio-cultural brasileiro, concorrem para aumentar a probabilidade de respostas adaptativas e aquelas que fomentam respostas desadaptativas, na adolescência. Esse conhecimento é fundamental para a elaboração de programas direcionados à juventude.

Sabe-se que o desenvolvimento psicossocial na adolescência é permeado por comportamentos de risco, definidos como sendo a participação em atividades que podem comprometer a saúde física e mental do jovem. Muitas dessas condutas podem assumir tão somente um caráter exploratório e acontecer sob a influência do meio; entretanto, em alguns casos, as condutas podem consolidar-se no repertório e associar-se a atitudes com significativas consequências negativas nos níveis individual, familiar e social ${ }^{7}$. Nesses casos pode-se falar em um processo de desadaptação social. Salienta-se que o conceito de adaptação (ou de desadaptação) aqui empregado refere-se à maneira como o indivíduo lida com o meio social, administra essa relação, conseguindo, no caso, conviver de forma bem sucedida em um ambiente que lhe oferece condições de vida que podem ser mais ou menos adversas?.

De acordo com o "modelo transacional", considera-se o desenvolvimento psicossocial de um indivíduo como resultado final do balanço (transação) entre os fatores de proteção e de risco presentes em diferentes esferas ${ }^{8}$. Os fatores protetores podem ser definidos como influências que modificam, melhoram ou alteram respostas pes- soais frente a adversidades (ou os fatores de risco) que predispõe a resultado desadaptativos ${ }^{9}$. Quanto aos riscos, postula-se que os fatores podem ser características, variáveis ou eventos que, se presente para um dado indivíduo, torna mais provável que ele, se comparado com outro selecionado da população geral, apresente um problema ou distúrbio ${ }^{10,11}$.

A literatura científica destaca os fatores de risco e de proteção mais consistentes no que se refere a comportamentos de risco na adolescência, especificamente no que concerne ao envolvimento com a prática de delitos. Abaixo, apresenta-se uma sistematização das principais evidências nesse campo, elencando os fatores e os indicadores relacionados, tendo por base algumas referências ${ }^{7,12,15}$.

Assim, o objetivo é descrever a experiência de adolescentes quanto à exposição a fatores de risco e de proteção no tocante ao desenvolvimento de comportamentos de risco, especificamente a conduta infracional.

\section{MÉTODO}

Participaram desse estudo 24 adolescentes do sexo masculino, sendo seis de cada uma das idades compreendida na faixa etária de 14 a 17 anos. Doze dos adolescentes foram recrutados em uma Escola Pública Estadual de uma cidade de porte médio no interior do Estado de São Paulo, que na ocasião da pesquisa estavam cursando o Ensino Médio. Esse grupo foi constituído por adolescentes indicados na própria escola por serem considerados com boa adaptação social (apresentavam rendimento acadêmico, não apresentavam problemas de comportamento na escola e não tinham envolvimento com álcool/drogas, nem histórico oficial de prática de atos infracionais).

Os outros doze adolescentes foram recrutados no Ministério Público de uma Comarca também localizada em cidade do interior do Estado de São Paulo, por ocasião da audiência de apresentação ao Promotor devido à apreensão policial por cometimento de ato infracional, sendo que metade desses adolescentes, ou seja, seis deles eram reincidentes, já haviam cometido outros delitos pelos quais já tinham um processo. Além da prática de delitos, a maior parte desses adolescentes apresentava o comportamento de uso de álcool e outras drogas, de acordo com as informações constantes no processo judicial.

Para a coleta de dados foi utilizado um roteiro de entrevistas organizado em torno das seguintes temáticas: infância, família, comportamento/ atitudes/crenças, escola/trabalho (atividades de rotina), lazer, amizades e experiências com álcool/ drogas e/ou infrações, baseado na literatura sistematizada sobre fatores de risco e de proteção. O roteiro semi estruturado estabeleceu, por temática, uma questão geral para orientar a coleta, do tipo "me fale um pouco da sua família", e previu 
Quadro 1: Principais fatores de risco para comportamentos de risco na adolescência apontados na literatura

\section{Domínio}

\section{Fatores familiares}

Práticas educativas familiares pobres

Alto conflito familiar

Comportamento de uso abusivo de álcool e outras drogas/Atitudes favoráveis ao uso de drogas

Atitudes favoráveis a comportamentos anti-sociais

Condições familiares desfavoráveis

Estrutura familiar desfavorável

\section{Fatores individuais: desenvolvimento} psicológico e comportamento

Rebeldia

Egocentrismo /Insensibilidade aos outros

Impulsividade, déficit de atenção e baixa capacidade verbal

Busca constante por sensações intensas

Iniciação precoce de comportamento antisocial

Atitudes favoráveis ao uso de drogas

Atitudes favoráveis ao comportamento anti-social

\section{Fatores acadêmicos / escolares}

Fracasso acadêmico

Pouco comprometimento com a escola

Condições escolares/institucionais desfavoráveis

\section{Fatores de risco no trabalho}

Fracasso no emprego

\section{Amigos}

Ter amigos/pares que apresentam comportamentos anti-sociais

Recompensa grupal por comportamento anti-social

Rejeição pelos colegas/isolamento

\section{Fatores de Risco}

\section{Indicadores}

Práticas caracterizadas por expectativas não claras para os comportamentos, ausência de limites, poucas e inconsistentes recompensas por comportamentos positivos, severas ou inconsistentes punição por comportamentos não desejáveis - disciplina pouco consistente e ineficiente, com alto índice de violência física, ausência/ abandono / negligência dos pais e vínculos afetivos fracos aumentam o risco de uso de drogas, violência e delinquência.

Crescer em famílias com muitos conflitos, mesmo se a criança não é envolvida diretamente.

Crescer em famílias cujos membros adultos apresentam história de alcoolismo ou uso abusivo de outras drogas, ou são tolerantes ao uso pela criança/adolescente, estão mais propensas a usar drogas.

Famílias nas quais os pais cometem comportamentos criminais ou são tolerantes ao envolvimento da criança/jovem em comportamentos criminais ou violentos.

Doenças ou incidentes em membros da família; morte ou doença dos pais e perda de entes queridos;Separação, divórcio ou novos casamentos dos pais; Viver em famílias monoparentais;

Falta de infra-estrutura básica para a moradia, renda familiar baixa, baixo nível de escolaridade dos pais / desemprego, moradia em cômodo pequeno para o número elevado de moradores (aglomeração).

\section{Indicadores}

Jovens que sentem que não fazem parte da sociedade, que não se sentem constrangidos pelas regras, que apresentam ausência de sentimento de culpa e tendem a ser hostis, se envolvendo frequentemente em brigas, destruição de patrimônio público, incidentes incendiários e vandalismo. Que não acreditam que serão bem sucedidos ou responsáveis ou que assumem uma postura rebelde ativa contra a sociedade.

Apresentar insensibilidade aos outros.

Jovens que mostram tendência a agir impulsivamente, sem reflexão, principalmente em situação de conflito.

Jovens que gostam de se envolver em comportamentos de risco e estimulantes.

Quanto mais cedo a manifestação de comportamentos anti-sociais, mais esse tende a ser frequente e duradouro. O mesmo raciocínio serve para o comportamento infracional e o de uso de álcool e outras drogas.. Nesse contexto, a institucionalização precoce, para tratamento, tende a incrementar os problemas de comportamento.

A iniciação do uso de qualquer substância é precedida por valores favoráveis ao seu uso. Jovens que expressam atitudes positivas em relação ao uso de drogas, incluindo menor percepção dos riscos do uso de substâncias.

Jovens que expressam atitudes positivas em relação à delinquência e à violência.

\section{Indicadores}

Fracasso acadêmico - baixo desempenho, comportamento agressivo em sala de aula defasagem escolar significativa, repetência escolar, falta de motivação para os estudos, frequentação irregular e/ou evasão escolar/ poucos anos de estudos / baixa escolaridade. frequentação irregular e/ou evasão escolar/ poucos anos de estudos / baixa escolaridade.
Intensa vontade de ser independente combinada com o pouco interesse/investimento escolar. Pouca supervisão familiar no que se referem à frequência escolar.

Não ter expectativas de continuar estudando. Falta de gosto pela escola, pouco ou nenhum tempo empregado em trabalhos de casa e percepção de que o trabalho de casa não relevante.

Escolas que mostram pouca clareza na implementação de regras, pouco reforço das mesmas (sem consequências para o comportamento de seguir corretamente às regras da escola) e instrução não efetiva (baixa qualidade de ensino).

\section{Indicadores}

Sentimento de não ter êxito no trabalho / viver insucessos nesse plano.

\section{Indicadores}

Frequentar pares que fazem uso abusivo de álcool e outras drogas, que portam armas e/ ou que fazem atos infracionais ou apresentam comportamentos violentos - adolescentes e/ou adultos.

Jovens que acreditam que seus amigos e colegas os aprovam e os admiram se eles se engajam no uso de drogas, na delinquência e na violência.

Jovens que se sentem rejeitados e são desprezados por seus colegas. 
Quadro 2: Principais fatores de proteção para comportamentos de risco na adolescência

\section{Domínio \\ Fatores familiares \\ Recompensas por envolvimento em atividades pró-sociais na família \\ Ligação/vínculos com a família \\ Relações familiares favoráveis \\ Disciplinamento consistente \\ Fatores individuais: desenvolvimento psicológico e comportamento \\ Temperamento "fácil"}

Atributos pessoais positivos

\section{Sociabilidade}

Religiosidade

Crença nos valores/regras morais

Envolvimento em tarefas sociais

\section{Fatores acadêmicos / escolares}

Bom desempenho acadêmico/ investimento na escolaridade

Ter bom relacionamento com os professores

Oportunidades de envolvimento em programas pró-sociais na escola

Recompensas por envolvimento em atividades pro sociais na escola

Ambiente escolar favorável

Condições escolares favoráveis

\section{Amigos}

Ligação a colegas com atividades prósociais

\section{Fatores de Proteção}

\section{Indicadores}

Jovens que percebem maior recompensa e reconhecimento por envolvimento em atividades pró-sociais na sua família estão mais propensos a participar em tais atividades.

Jovens que tem bom relacionamento com os pais e reportam forte ligação emocional com os mesmos (ou tutores legais) laços afetivos.

Crescer em um ambiente familiar livre de violência, que apresenta coesão, senso de pertencimento, aconchego e estabilidade, no qual as relações são permeadas por afeto, diálogo, equilíbrio de poder/limites, respeito mútuo/reciprocidade, apoio/suporte, cuidados adequados.

Disciplina consistente, com uma educação apoiada na supervisão (apresentação clara de limites).

\section{Indicadores}

Crianças/jovens que têm um temperamento considerado fácil e que se recuperam rapidamente de incidentes emocionais.

Atributos disposicionais como autonomia, auto-estima elevada, inteligência, bem-estar subjetivo e orientação social positiva (representação mental de afeto positivo), além de competência emocional, senso de humor, otimismo, tolerância ao sofrimento e estabilidade emocionalHabilidade para a resolução de problema, capacidade de tomar decisões, avaliação das experiências como desafios (e não como ameaças). Capacidade para vislumbrar o futuro e planejá-lo, e ter expectativa de sucesso no futuro.

Crianças/jovens que são socialmente extrovertidas e tem personalidade agradável.

Jovens que reportam mais frequentemente envolvimento em atividades religiosas organizadas.

Jovens que guardam crenças morais fortes.

Jovens que mostram maior participação em tarefas sociais (ex. resolução de problemas sociais, grande respeito e tolerância ao outro, melhor comunicação).

\section{Indicadores}

Frequentar a escola, apresentar bom desempenho / rendimento acadêmico, fazer tarefas.

Manter bom relacionamento com professores ou pessoas significativas, que assumam papel de referência segura, que faça o jovem se sentir querido no ambiente escolar.

Jovens que participam de atividades acadêmicas, que fazem as tarefas escolares e percebem mais oportunidades para o envolvimento em atividades pró-sociais na escola.

Jovens que percebem maior recompensa por envolvimento em atividades pró-sociais na escola estão mais propensos a participar em tais atividades.

Escolas que promovem relação de afeto, de respeito, de diálogo e de confiança entre alunos, professores e gestores, incrementando a sociabilidade no ambiente escolar e valorizando os estudantes, enquanto protagonistas, propiciam a construção de um sentido de pertencimento, o que atua como fator de proteção.

Escolas que oferecem rotinas e atividades que vão além dos horários escolares, trabalho coletivo, estabilidade de recursos financeiros e materiais necessários às atividades.

\section{Indicadores}

Jovens que reportam forte ligação emocional a colegas que estão engajados em comportamentos pró-sociais e que se abstém de drogas e de comportamentos delinquentes, que mantém bom relacionamento com os amigos. também uma série de tópicos indicativos de informações importantes de serem coletadas, de acordo com os apontamentos da literatura sobre risco e proteção revisada.

O tratamento dos dados baseou-se na técnica de Análise de Conteúdo proposta por Bardin ${ }^{16}$. Cada entrevista foi analisada qualitativamente para uma melhor compreensão de seus conteúdos e para a categorização das respostas; além disso, procedeu-se à análise quantitativa, sendo observadas as frequências de respostas em cada cate- goria, em cada um dos grupos estudado. Posteriormente procedeu-se a uma comparação dos grupos com vista a sublinhar as diferenças e semelhanças entre eles e colocar em destaque o que pareceu mais significativo em termos de exposição a risco e a proteção para o grupo de adolescentes judiciarizados.

Esse estudo foi desenvolvido no quadro de um projeto de pesquisa maior, que foi analisado e aprovado no Comitê de Ética da FFCLRP- USP (protocolo do CEP no 2019.0.000.222-08). 


\section{RESULTADOS E DISCUSSÃO}

Os resultados obtidos no tocante a cada um dos grupos são apresentados de modo sintetizado nos quadros 3 e 4 . Primeiramente, expõem-se os resultados da análise dos relatos dos adolescentes considerados com boa adaptação social e, em se- guida, os da análise dos relatos dos adolescentes com envolvimento em práticas de atos infracionais. Para cada grupo são apresentadas as categorias identificadas a partir do conteúdo das entrevistas e a frequência de respostas (adolescentes) na categoria em questão. Na sequência explana-se sobre a comparação dos dois grupos.

Quadro 3: Fatores de risco e de proteção identificados na amostra dos adolescentes com boa adaptação social

\section{FATORES DE RISCO}

\section{FATORES DE PROTEÇÃO}

\section{FAMÍLIA / (PAIS RESPONSÁVEIS)}

Vivenciaram a separação dos pais (2)boa adaptação social.

Vivem em família monoparental (1)

Vivem em família reconstituída (2)

Morte do pai (1)

Responsável desempregado (pai) (1)

Presenciou muitos conflitos na família (1)

Cresceram em famílias com membros (adultos) com histórico

de alcoolismo (3)

Doença crônica (mental) ou acidente, ocasionando problema

crônico de saúde, dos responsáveis (2)

Disciplinados por meio de violência física (no passado) (3)

Se ressente da distância, no relacionamento, com as figuras

parentais (1)
Vivem em ambientes familiares coesos. Há conflitos, mas esses parecem ser geridos com vistas à manutenção da família e não parece haver recorrência à violência para a resolução dos problemas (8)

Submetidos a práticas educativas disciplinares consistentes supervisão, diálogo e castigos não corporais (9) Bom relacionamento com os pais (8)

\section{ESCOLA}

Sentem-se desmotivados em relação aos estudos (4)

Tem histórico de repetência escolar (2)

Comportamento agressivo/perturbador em sala de aula/escola (no passado) (1)
Frequentam a escola (12)

Consideram ter bom desempenho escolar (10)

Tem bom relacionamento com os professores (atualmente) (10) Tem interesse pelos estudos/gosta das matérias e planos/ projetos relacionados à escolarização (expectativas acadêmicas) (9)

Participam de atividades pró-sociais na escola, em horários extraaulas (6)

\section{RELAÇÃO COM PARES}

Sentem-se desmotivados em relação aos estudos (4)

Tem histórico de repetência escolar (2)

Comportamento agressivo/perturbador em sala de aula/escola

Evitam associar-se a pares que usam drogas e/ou que apresentam comportamento anti-social (4)

(no passado) (1)

\section{DESENVOLVIMENTO PSICOLÓGICO / COMPORTAMENTO}

Histórico de comportamento anti-social (embora não criminalizado/oficializado) (3)

Impulsividade (3)

Envolveu-se com frequência em brigas (no passado) (1)
Costumam refletir e planejar antes de agir em situação de conflito (6)

OBS: Os números em parênteses se referem aos adolescentes que se encaixam em cada categoria.

Tal como preconizado pelo modelo transacional, os resultados evidenciam que os adolescentes com boa adaptação social são expostos a fatores de risco, mas experienciam fatores de proteção que parecem garantir o desenvolvimento.

O domínio em que parece haver mais fatores de risco é o da "família". Destaca-se que as categorias elencadas, em sua maioria, referem-se a eventos adversos na história familiar, no sentido de alterar sua configuração inicial: separação/divórcio ou perda de um dos genitores, por morte, concorrendo para rearranjos na sua configuração (monoparentalidade e reconstituição). Ainda na esfera familiar, chama a atenção, em termos de risco, o fato de os pais/responsáveis, em alguns casos, apresentarem problemas eles mesmos de natureza crônica - transtorno relativo à saúde, à saúde mental e histórico de alcoolismo -, o que implica na exposição dos filhos a adversidades, em longo prazo. No que respeita mais propriamente à dinâmica das relações, há menção à existência de um certo "distanciamento" na relação entre adolescente-pais/responsáveis. Porém, de acordo com os relatos obtidos, um aspecto problemático mais preponderante seria a violência intra-familiar, tanto no plano das práticas parentais (tendo alguns adolescentes afirmado que "apanhavam"), quanto no plano do relacionamento entre os adultos/cônjuges (havendo indicações quanto à existência de muitas brigas/discórdias). É preciso sublinhar, todavia, que a exposição a tais fatores de risco, segundo os relatos, estaria circunscrita ao passado, não se fazendo mais presentes.

No que concerne a eventos que podem ser considerados como risco, denota-se também o advento do "desemprego" dos responsáveis, embora esse fator possa ser pensado como circunstancial, com probabilidade de ser superado antes de provocar alterações substanciais no funcionamento familiar. 
Quanto ao que parece funcionar como proteção, no nível da família, prevaleceria nesse âmbito fatores relacionados à dinâmica das relações, ou seja, a totalidade das referências feitas pelos adolescentes indicou a existência de interações de qualidade, no interior da família (além da ausência de violência, no presente), o que concorreria para produzir coesão familiar e vinculação do adolescente a pelo menos um dos responsáveis. Tal característica funcional, atuando no presente, parece suplantar o impacto negativo de eventos adversos e/ou de dificuldades parentais, crônicas e/ou circunstanciais, contribuindo para o desenvolvimento adaptativo do adolescente.

No que se refere à dimensão "escola" e aos possíveis fatores de risco presentes na vida escolar dos adolescentes, poucas foram as indicações feitas nesse grupo. Alguns referiram sentirem-se desmotivados em relação aos estudos, outros afirmaram ter um histórico de repetência e um relatou que já tivera problemas de comportamento na escola (embora isso não valesse mais para o presente). Contudo, várias foram as indicações a aspectos positivos envolvendo a vida escolar, que parecem funcionar como fator proteção desses adolescentes. Além do fato de todos os adolescentes desse grupo estarem estudando, ou seja, frequentando regularmente a escola, os apontamentos sobre a experiência escolar indicaram que a maioria teria bom desempenho e interesse pelos estudos, expressando gostar de determinadas matérias, além de ter expectativas acadêmicas para si, no sentido de o planejamento do futuro implicar "continuidade dos estudos" (em nível técnico e em nível universitário). Em âmbito escolar, destacaram-se também as indicações com respeito ao bom relacionamento com alguns professores. Ademais, alguns referiram, também, estar engajados na participação de atividades pró-sociais oferecidas pela escola, em horários extra-aulas, indicando ser a escola um espaço de socialização mais amplo. Destes resultados depreende-se a idéia de que o contexto escolar se apresenta para esses adolescentes, em sua maioria, como um ambiente positivo, onde tecem laços saudáveis, empenham-se e engajam-se nas atividades escolares e extra-escolares, estabelecendo para si expectativas de natureza acadêmica. De todas as dimensões estudadas foi no nível escolar que houve o maior número de indicação relacionada a fatores de proteção.

Já no domínio amigos/pares, o risco e a proteção experienciados referem-se à escolha dos colegas/amigos. Dentro disso, verificou-se o fato de alguns adolescentes terem colegas apresentando condutas divergentes, especialmente a de consumo de drogas ilícitas. Porém, outros adolescentes indicaram o oposto, afirmando evitar associar-se a pares envolvidos com drogas e/ou qualquer outro comportamento anti-social, procurando manter-se ligados a adolescentes com comportamento prosocial, o que funcionaria como fator de proteção.

No plano do desenvolvimento psicológico, concernindo atitudes e comportamentos, segundo o relato de alguns adolescentes, além da característica de agir impulsivamente, de maneira irrefletida, em algumas situações sociais, o histórico de problemas de comportamento, como o envolvimento frequente em brigas com pares, poderia ser destacado como fator de risco ao desenvolvimento. Por outro lado, como proteção, nesse mesmo plano, também de acordo com o relato dos adolescentes, denotar-se-ia a habilidade de refletir e planejar uma ação, procurado tomar decisões baseadas em menor prejuízo, em uma situação de conflito.

A seguir é apresentado o quadro síntese dos resultados obtidos para os adolescentes envolvidos com a prática de delitos.

Constatou-se que aos adolescentes em conflito com a Lei, tal como os com boa adaptação social, também vivenciam a exposição a fatores de risco e a fatores de proteção. Porém, na transação entre esses fatores supõe-se, devido à presença da prática infracional persistente, que a proteção oferecida pelos fatores identificados não seja suficiente para compensar o impacto negativo dos fatores de risco aos quais são submetidos.

No domínio da "família", é interessante notar que os adolescentes desse grupo, tal como os do outro grupo, também teriam vivido eventos que impactaram a constituição familiar, como a morte do pai e a dissolução do núcleo de origem por separação do casal, passando a viver em famílias monoparentais ou reconstituídas.

Nesse grupo, igualmente, denota-se a experiência de viverem com adultos apresentando eles mesmos algumas problemáticas crônicas como o alcoolismo, mas também, nesse plano, a particularidade de conviverem com adultos criminalizados. No que concerne a eventos, denota-se também o advento do "desemprego" dos responsáveis, embora esse fator possa ser pensado como circunstancial.

Em termos de dinâmica familiar, sublinha-se que os adolescentes consideraram viver em contextos marcados por muitos conflitos, serem disciplinados por meio práticas de punição corporal (violência física) e/ou submetidos a práticas educativas pouco consistentes (pouca ou nenhuma regra), devendo-se destacar o fato de tais apontamentos fazerem referência ao momento presente.

Com relação aos fatores protetores, no contexto da família, encontrou-se para esse grupo, exatamente as mesmas indicações que no grupo de adolescentes com boa adaptação social: viver em ambiente familiar coeso, ser submetido a práticas educativas consistentes e ter bom relacionamento com pelo menos um dos responsáveis.

No domínio da "escola", de um lado, destaca-se a desmotivação de muitos com relação aos estudos, sendo que a maioria teria evadido a escola, denotando-se nesse grupo, de modo mais significativo, repetência e defasagem na escolaridade, associadas a baixo desempenho escolar. Ademais, alguns dos adolescentes desse grupo também referiram o fato de a escolarização ter sido 
Quadro 4: Fatores de risco e de proteção identificados na amostra dos adolescentes envolvidos com a prática de atos infracionais

\section{FATORES DE RISCO}

FAMÍLIA / (PAIS RESPONSÁVEIS)

\section{FATORES DE PROTEÇÃO}

Vivenciaram a separação dos pais (3)

Vivem em família reconstituída (3)

Vivem em família monoparental (2)

Morte do pai (1)

Responsável desempregado (pai) (1)

Cresceram em família com membros (adultos) com histórico de alcoolismo (3)

Responsável envolvido com a prática de atos criminosos (1)

Vivem em famílias que apresenta muitos conflitos (4)

Disciplinados por meio de violência física (2)

Prática educativa/disciplina pouco consistente (1)

Se ressentem da distância, no relacionamento, com as figuras

parentais (5)

Sentem desmotivados em relação aos estudos (9)

Tem histórico de repetência escolar (4)

Apresentam defasagem idade/série (6)

Evasão escolar/interromperam os estudos (9)

Comportamento agressivo/perturbador em sala de aula/escola

(no passado) (7)

\section{RELAÇÃO COM PARES}

Encontram-se associados a adolescentes e/ou a adultos

infratores/criminosos (10)

Encontram-se associados com colegas que fazem uso de drogas

(9)

\section{DESENVOLVIMENTO PSICOLÓGICO / COMPORTAMENTO}

Histórico de comportamento anti-social: fazem ou já fizeram uso de bebidas alcoólicas e/ou outras drogas (8)

Impulsividade (9)

Não se sentem constrangidos por regras (8)

Referem ausência de sentimento de culpa (relacionada a

situações de brigas, quando feriram alguém) (5)
Vivem em ambiente familiar coeso. Há conflitos, mas esses parecem ser geridos com vistas à manutenção da família e não parece haver recorrência à violência para a resolução dos problemas (4)

Submetidos a práticas educativas disciplinares consistentes supervisão diálogo e castigos não corporais (4)

Bom relacionamento com os pais (6)

ESCOLA

Frequentam a escola (3)

Tinham bom relacionamento com os professores (no passado) (3)

Costumam refletir e planejar antes de agir em situação de conflito (6)

OBS: Os números em parênteses se referem aos adolescentes que se encaixam em cada categoria.

marcada pela apresentação de problemas de comportamento na escola/sala de aula, indicando dificuldade na adaptação escolar.

Por outro lado, enquanto proteção, a frequência escolar é um fator que caracterizou poucos adolescentes, sendo que poucos também referiram ter experienciado bom relacionamento com os professores, o que teria como efeito maior o engajamento dos adolescentes com a própria escolarização.

No domínio "pares", apenas duas indicações referentes a fatores de risco foram identificadas nesse plano; essas, porém, foram feitas pela maioria dos adolescentes: a associação a adolescentes e/ou adultos infratores/criminosos e a amigos usuários de drogas ilícitas. No tocante ao que poderia funcionar como proteção, há que se notar que nenhuma indicação feita se referiu a fatores que poderiam atenuar o impacto dos riscos.

No plano "pessoal" encontrou-se um número expressivo de indicações de fatores de risco. Em termos de comportamento, denota-se a persistência em condutas de risco, que parece indicar um desenvolvimento psicossocial atípico. A maioria dos adolescentes desse grupo já havia cometido infrações como, por exemplo, dirigir sem habilitação, participar de brigas em que hou- ve lesão corporal, portar e traficar drogas, portar armas e roubar. A maioria também afirmou ter feito ou ainda fazer uso de bebidas alcoólicas e/ ou outras drogas com regularidade, cabendo salientar que a maioria deles disse ter iniciado o envolvimento com tais substancias precocemente, entre 10 e 13 anos de idade. No que concerne a aspectos psicológicos, a maioria dos participantes indicou agir impulsivamente, sentindo-se pouco constrangidos pelas regras, em diferentes contextos, além de mencionarem não sentir culpa relacionada às situações em que, em brigas, haviam ferido alguém.

Como contraponto, no nível atributos pessoais, houve quem referisse ser reflexivo, pensar e planejar antes de agir em situações de conflito (ou seja, não ser impulsivo).

\section{Diferenças e semelhanças entre os grupos}

A comparação dos grupos estudados visa salientar as diferenças e semelhanças entre eles e, assim, colocar em destaque o que parece efetivamente significativo em termos de exposição a riscos e proteção, no nosso contexto, no tocante ao envolvimento de adolescentes com a prática de atos infracionais. 
Num primeiro plano, destaca-se o fato de todos os adolescentes, independentemente do grupo estarem expostos a uma gama variada de fatores de risco, sendo que grande parte desses parece se concentrar no domínio "família". O que diferencia os grupos nessa dimensão parece ser mais propriamente a natureza do risco que prevalece, no presente, para os adolescentes engajados em prática de atos infracionais: eles estariam ainda experienciando uma dinâmica familiar marcada por conflitos e sendo submetidos a práticas parentais inadequadas, que incluem a violência física. Deve-se sublinhar que os eventos adversos que incidiram nas famílias, alterando sua constituição, bem como algumas das problemáticas apresentadas pelos adultos (o alcoolismo particularmente) são equivalentes nos dois grupos, o que faz supor que não desempenhem um papel tão relevante em relação à problemática em foco. Nesse plano, é mais significativo o fato de os adolescentes infratores terem como diferencial à exposição a adultos criminalizados, o que pode funcionar como modelo.

Com relação aos fatores protetores relativos a essa dimensão, verifica-se que em ambos os grupos tem-se indicações da mesma natureza. O que diferencia os grupos tem mais a ver com a quantidade de meninos que fizeram indicações referentes a tais fatores, num e noutro grupo, sendo que em meio aos adolescentes com boa adaptação social esses se fariam mais presentes.

No que concerne ao domínio "escola", diferenças importantes marcam os grupos. A mais forte delas, no que se refere à exposição ao risco, diz respeito ao fato de muitos dos adolescentes em conflito com Lei encontrarem-se evadidos da escola. É preciso, contudo, considerar que o fato de nenhum dos adolescentes com boa adaptação apresentar essa característica decorre do viés criado pelo próprio método de pesquisa, em função do qual se decidiu recrutar os participantes desse grupo no contexto escolar.

Outro ponto importante a ser destacado, nesse contexto, diz respeito à significativa diferença entre os grupos no que se refere às indicações de fatores de proteção nesse contexto. De um lado, percebe-se que para o grupo com boa adaptação uma gama variada de aspectos positivos permeia suas experiências escolares, o que parece funcionar como proteção, no sentido de favorecer uma ligação boa e forte com a própria escolarização. Do outro lado, há poucas indicações feitas por poucos adolescentes infratores sobre aspectos positivos evolvendo a escola, que poderiam funcionar como proteção.

Em relação ao "relacionamento com os pares", destaca-se o fato de em ambos os grupos haver indicações de associação dos adolescentes estudados com outros que consomem drogas. A diferença entre os grupos, em termos de exposição a fatores de risco, parece residir no fato de os adolescentes infratores fazerem associações com outros adolescentes que apresentam comportamento infracional, além do de uso de drogas. Em paralelo, ainda no tocante ao convívio com "pares", destaca-se a nítida diferença no plano dos aspectos que podem funcionar como proteção. No grupo com boa adaptação tem-se a indicação de que os adolescentes evitam associar-se a pares envolvidos com drogas e/ou que apresentam comportamentos anti-sociais, o que indica um processo de escolha de "amigos" que, além de regular as influências sofridas, denota a adoção de determinados valores e crenças que podem ser protetivos, ao passo que em meio aos infratores não há menção a qualquer variável que possa funcionar como proteção, nesse plano.

No tocante ao "desenvolvimento psicológico/ comportamento", o grupo dos adolescentes infratores se destacou em relação ao número e à natureza das indicações. Destaca-se aqui o fato de que todos os adolescentes desse grupo referiram ter um histórico de prática de atos infracionais (mesmo que não conhecidas da justiça), o que denota a implicação dos mesmos com tais práticas, sugerindo a consolidação do problema. Há que se ressaltar ainda que no grupo de adolescentes judiciarizados houve referência ao fato de consumirem bebidas alcoólicas e/ou outras drogas. Tais comportamentos, além de serem comportamentos de risco em si, e estarem associados a fatores específicos, também podem ser entendidos como aspectos que aumentam a probabilidade de os sujeitos apresentarem novos problemas, como o envolvimento com práticas de atos infracionais, por exemplo.

É preciso, contudo, atentar para o fato de essa problemática (consumo de álcool e outras drogas) não aparecer em meio aos adolescentes com boa adaptação por que constituiu-se em critério de seleção da amostra, o que acaba por gerar um viés na comparação, nesse âmbito. Estudos futuros deverão preocupar-se em controlar essa variável por ocasião da comparação dos grupos em foco.

No mais, nota-se que um número maior de adolescentes infratores indicam um rol mais diversificado de aspectos psicológicos que podem funcionar como fator de risco para a emissão de comportamento infracional. Vale, entretanto, frisar que tais aspectos ao mesmo tampo em que devem ser concebidos como fator de risco, podem também ser pensados como resultado de um processo de desenvolvimento psicososcial perpassado pela exposição crônica a inúmeros outros fatores ambientais.

Em relação aos fatores de proteção, nesse plano pessoal, constatou-se um equilíbrio entre os grupos, sendo que tanto para o grupo com boa adaptação social quanto para o de judiciarizados encontrou-se indicações da mesma natureza, referentes à capacidade refletir antes de agir/planejar o comportamento em situação de conflito. Embora tais resultados tenham algum valor, é preciso pensar que tais indicações remetem a aspectos de difícil avaliação, sendo que falar sobre isso difere do fato de apresentar as características em situações concretas. 
A maior parte dos adolescentes foi ou são expostos a uma série de fatores de risco, mas o que vale na determinação dos comportamentos de tais adolescentes é o equilíbrio que existe entre o número e a qualidade do risco e da proteção, nas diferentes dimensões ${ }^{14}$. Seria ingênuo pensar que somente um fator de risco pudesse acarretar problemas a quem a ele está exposto. De um lado, há evidencias de que a probabilidade de um indivíduo desenvolver problemas de comportamentos aumenta exponencialmente com a exposição a cada fator de risco adicional, até o nível de risco tornar-se extremamente elevado ${ }^{17}$. De outro lado, a ausência de fatores de proteção, como contraponto aos riscos, também se constitui em problema. As intervenções de prevenção - tanto no nível primário como secundário - deveriam o tempo todo visar esses dois eixos: diminuir ou eliminar fatores de risco, na medida do possível, e incrementar ou instaurar fatores de proteção ${ }^{18}$.

No que se refere ao domínio "família", sabese que a coesão familiar é um fator importante que contribui para amenizar os efeitos das adversidades $^{19}$. Relações familiares saudáveis, desde o nascimento da criança, servem como fator de proteção para toda a vida mas, particularmente, para o adolescente ${ }^{20}$. A presença e o apoio familiar podem ser efetivos na redução do impacto da exposição do indivíduo a eventos de vida estressores, pois o vínculo e as interações servem como apoio emocional, o que é a base para o desenvolvimento pleno das potencialidades das crianças e adolescentes ${ }^{20}$.

Ademais, os padrões de comportamentos, as atitudes, bem como a conduta dos pais e dos irmãos, são modelos importantes para os adolescentes e o estabelecimento de regras e disciplina consistentes favorece o comportamento social e o desempenho acadêmico ${ }^{21,22 .}$

Em suma, famílias que apresentam coesão e disciplina consistente são mais propensas a ter membros saudáveis ${ }^{23}$.

No tocante à "escola", em períodos que se seguem a infância, as experiências vividas passam a ter grande importância, tornando-se fonte de influência no comportamento, já que a participação dos indivíduos nesse ambiente se torna cada vez mais ativa. É nítido a influencia da escola no desenvolvimento da personalidade, valores e relações sociais $^{24}$. Na adolescência, principalmente, o indivíduo amplia seus círculos de interação e atividades, e o ambiente escolar passa a ter um papel mais marcante, de modo a influenciar o comportamento no sentido dele ser adaptativo ou, por outro lado, inadequado. Isto dependerá da qualidade das relações e da presença de afetividade e reciprocidade que tal ambiente propiciar ${ }^{23}$. Assim, a participação na escola é entendida como fator de proteção quando oferece relacionamentos positivos que fomentem a auto-estima e a auto-eficácia dos adolescentes ${ }^{25}$. Como já mencionado, manter bom relacionamento com os professores é muito importante para o bem estar do indivíduo na escola.
Manter bom relacionamento com amigos, professores ou pessoas significativas, que assumam papel de referência segura ao indivíduo, e que o faça sentir-se querido e amado, são considerados importantes fatores de proteção, já que favorecem a adequada adaptação na escola.

A guisa de conclusão, reitera-se, com base nos resultados obtidos, que os adolescentes com boa adaptação social, em contraposição àqueles com envolvimento infracional, parecem beneficiarse de um número maior de fatores protetivos, destacando-se, nesse plano, o domínio escolar, no qual denota-se significativos aspectos que parecem funcionar como proteção ao desenvolvimento social dos jovens. Por outro lado, os dois grupos se assemeIharam no tocante à exposição a fatores de risco, nos diferentes domínios investigados. A diferença nesse plano, especificamente na "família", referese à indicação, no caso dos adolescentes em conflito com a Lei, de a convivência familiar parecer permeada por mais conflitos e esses tenderem a ser resolvidos por meio de comportamentos coersitivos (agressivos). Dentro disso, destaca-se que os infratores relataram terem sido (durante a infância) e ainda serem (na própria adolescência) disciplinados por meio de punições físicas/corporais (o que indicaria a existência de abusos ao longo de todo o desenvolvimento), ao passo que os adolescentes com boa adaptação social teriam sido submetidos a tais práticas disciplinares somente na infância (não mais na adolescência). Ademais, no que concerne à exposição a fatores de risco, destaca-se o fato de os adolescentes infratores indicarem a convivência com adultos criminalizados (julgados e condenados por condutas ilegais/ criminosas), seja no interior da família, seja no plano das relações de amizades (pares), sendo que esse aspecto não aparece no relato de qualquer dos jovens com boa adaptação social.

Tem-se debatido com vigor as falhas das instituições sociais para apoiar e proteger o jovem. A atuação das instituições básicas, responsáveis pela socialização, como a família e a escola, passa por séria crise no exercício de suas funções sociais. Todavia, de acordo com Dryfoos ${ }^{26}$ é preciso reconhecer que a família e a escola são locais privilegiados para a implantação de programas de prevenção, com a primeira impactando positivamente a primeira infância e a segunda, influenciando desde a segunda infância. Em outros países, tem-se desenvolvido programas, a maior parte em escolas, buscando a prevenção primária do desenvolvimento de comportamentos de risco em meio aos jovens, com a introdução de conteúdos específicos e consequente alteração do currículo escolar, o treinamento de educadores, o aconselhamento e o trabalho voluntário. Tais programas visam prover estimulação intelectual, aumentar as habilidades cognitivas e aumentar o sucesso acadêmico futuro. A escola por ser um espaço de formação é um contexto favorável à efetivação de diálogo entre os membros de um grupo e ao uso do tempo livre para 
propiciar interesses pessoais, inibindo o surgimento da delinquência. Estudos sobre a efetividade desses programas mostram a consistência dos resultados do sucesso escolar sobre a prevenção da delinquência ${ }^{27}$.

Outro foco de intervenção tem sido a influência dos pares, considerando que esses parecem ter uma influência sobre a conduta delituosa dos adolescentes. Os programas com esse prisma, quando realizados em escolas, buscam estimular que alguns adolescentes tomem a posição de líderes positivos, influenciando os demais através da modificação de comportamentos do grupo ${ }^{27}$.

As estratégias de prevenção para a violência juvenil têm sido pouco priorizadas, no Brasil. A noção de prevenção nessa área encontra-se ainda muito dissociada das propostas de atuação das instituições brasileiras, talvez, devido às lacunas no conhecimento quanto aos fatores que parecem efe-

\section{REFERÊNCIAS}

1. Sapienza G, Pedromônico MRM. Risco, proteção e resiliência no desenvolvimento da criança e do adolescente. Psicologia em Estudos, Maringá 2005; 10 (2): 209-216.

2. Cruz-Neto O, Moreira MR. Trabalho infanto-juvenil: motivações, aspectos legais e repercussão social. Cadernos de Saúde Pública 1998; 14 (2): 437- 441.

3. Lemos SL, Vasconcelos MS. Modelos organizadores do pensamento: uma perspectiva de pesquisa sobre o raciocínio moral com adolescentes autores de infração. Psicologia em Estudo 2003; 8 (2): 47-59.

4. Toledo GW, Bazon MR. A delinquência Juvenil no estado de São Paulo: estudo de sua evolução entre 1950 e 2002. In: Biasoli-Alves ZMM, Mattiusso IMF, Carvalaes LHR, Duarte P. (Org.). Programa de Pós-Graduação em Psicologia: Livro de Artigos - Tomo II. Ribeirão Preto: Legis Summa; 2005. p. 299-309.

5. Minayo MCS. A violência na adolescência: um problema de saúde pública. Cadernos de Saúde Pública 1990; 6 (3): 278-292.

6. Minayo MCS. A violência social sob a perspectiva da saúde pública. Cadernos de Saúde Pública 1994; 10 (supplement1): 07-18.

7. Feijó RB, Oliveira EA. Comportamento de risco na adolescência. Jornal de Pediatria 2001; 77(supplement 2): 125-134.

8. Olson SL, JE Bates, Sandy JM, Lanthier R. Early developmental precursors of externalizing behavior in middle childhood and adolescence. Journal of Abnormal Child Psychology 2000; 28 (2): 119-133.

9. Rutter M. Resilience in the face of adversity: protective factors and resistance to psychiatric disorder. British Journal of Psychiatry 1985; 147: 598-611. tivamente relacionados à problemática, no sentido de aumentar ou de diminuir sua ocorrência.

O estudo aqui relatado teve por meta contribuir justamente nesse tocante. Pesquisas futuras devem testar as informações obtidas e investigar de modo mais sistemático e aprofundado um conjunto maior de variáveis, de acordo com as indicações da literatura. Dentro disso, vale a ressalva de que será imprescindível ampliar as investigações para também envolver variáveis de natureza comunitária, na medida em que o engajamento de adolescentes com a prática de ato infracional apresenta-se fortemente associada a características da localidade em que reside ${ }^{14}$. Outro limite a ser ultrapassado refere-se à importância de obter dados por meio de outras fontes que a do próprio adolescente, bem como a necessidade de usar instrumentos padronizados para a coleta de informações, sobretudo no que se refere a aspectos do desenvolvimento psicológico dos adolescentes.

10. Garmesy N. Stressors of Childhood. In: Garmesy N, Rutter M. Eds. Stress, Coping and Development in Children. New York, NY: McGraw-Hill; 1983.

11. Werner EE, Smith RS. Overcoming the Odds. High Risk Children from Birth to Adulthood. New York, NY: Cornell University Press; 1992.

12. Arthur, MW, Hawkins JD, Pollard JA, Catalano $\mathrm{RF}$, Baglioni AJ, Jr. Measuring risk and protective factors for substance use, delinquency, and other adolescent problem behaviors. Evaluation Review 2002; 26 (6): 575-601.

13. Silveira JM, Silvares EFM, Marton SA. Programas preventivos de comportamentos anti-sociais: Dificuldades na pesquisa e implementação. Estudos de Psicologia 2003; 20 (3): 59-67.

14. Gallo AE, Williams, LCA. Adolescentes em conflito com a lei: uma revisão dos fatores de risco para a conduta infracional. Psicologia teoria e Pratica 2005; 7 (1): 81-95.

15. Andrews DA, Bonta J. The Psychology of criminal conduct.4th ed. Canadá: LexixNexis; 2006.p.79-93.

16. Bardin L. Análise de conteúdo. 70 ed. Lisboa; 1977. p. 54-71.

17. Coie JD, Watt NF, West SG, Hawkins JDJ, Asarnow $\mathrm{JR}$, Markman HJ, et al. The science of prevention: A conceptual framework and some directions for a national research program. American Psychologist 1993; 48 (10): 1013-1022.

18. Haggerty RJ, Sherrod LR, Garmezy N, Rutter M. (2000). Stress, risk and resilience in children and adolescents: process, mechanisms and interventions. Cambridge, UK: Cambridge University Press, 1994, 417 p.

19. Yunes MAM, Garcia NM, Albuquerque, BM. Monoparentalidade, pobreza e resiliência: Entre as crenças dos profissionais e as possibilidades da convivência familiar. Psicologia: Reflexão e Crítica 2007; 20 (3): 444-453. 
20. Schenker M, Mynaio MCS. Fatores de risco e proteção para o uso de drogas na adolescência. Ciências e Saúde Coletiva 2005; 10 (3): 707-717.

21. Berne E. O que você diz depois de dizer olá? : a psicologia do destino. São Paulo: Nobel; 1988. p.77-83.

22. Souza MTS. Script de vida: histórias entrelaçadas [dissertação de Mestrado]. Campinas: Faculdade de Ciências Médicas da Universidade Estadual de Campinas; 1998. p.15-26.

23. Koller M, Polleto SH. Contextos ecológicos: promotores de resiliência, fatores de risco e de proteção. Estudos de Psicologia 2008; 25 (3): 405-416.

24. Chiapetti N. Comportamento de risco em préadolescentes e contextos de convivência: influencia do contexto escolar. Revista Eletrôni- ca de Psicologia 2003 [acesso em 11 de jan 2012]; (1):1-10. Disponível em: http:// www.utp.br/psico.utp.online

25. Costa LG, Dell'Aglio, DD. A rede de apoio social de jovens em situação de vulnerabilidade social. In: Libório RMC, Koller SH. (Org.). Adolescência e juventude: Risco e proteção na realidade brasileira. 1 ed. Itatiba, São Paulo: Casapsi Livraria; 2009. p. 219-263.

26. Dryfoos J. Adolescents at Risk. Oxford University Press: New York; 1990. p. 115122.

27. Assis S, Constantino P. Violência contra crianças e adolescentes: o grande investimento da comunidade acadêmica na década de 90. In: Minayo MCS, Souza ER (orgs.). Violência sob o olhar da saúde. Rio de Janeiro: Fiocruz; 2003. p. 163-198. 